\title{
Vagotomia modifica o efluxo do cálcio nas ilhotas pancreáticas
}

\section{Vagotomy changes calcium eflux in pancreatic islets}

\author{
Carlos A. Silva ${ }^{1}$, Adriano C. R. Pardi², Eder J. Arruda ${ }^{3}$, Daniel O. Grassi ${ }^{3}$, Maria T. M. Severi ${ }^{4}$, \\ Antonio A. Gonçalves ${ }^{5}$
}

\begin{abstract}
RESUMO
A participação do sistema nervoso parassimpático na modulação da secreção de insulina manifesta-se claramente durante a fase cefálica que se segue ao estímulo iniciado pelo estímulo sensorial provocado pela presença do alimento na cavidade oral. O objetivo deste trabalho foi avaliar se a vagotomia subdiafragmática seletiva do ramo pancreático poderia modificar a permeabilidade ao $\mathrm{Ca}^{2+}$ da membrana plasmática das células beta. Para avaliar os efeitos da vagotomia usamos o principal secretagogo que é a glicose e o potencializador carbamilcolina. Os estudos de efluxo de ${ }^{45} \mathrm{Ca}^{2+}$ foram realizados em ilhotas de ratos controle ou desnervados isoladas por digestão com colagenase e perfundidas com KREBS contendo os secretagogos. As ilhotas isoladas de ratos 15 e 30 dias após a vagotomia do ramo pancreático não responderam ao estímulo com 16,7 mM de glicose e também apresentaram alteração na sensibilidade à carbamilcolina (CCh $100 \mu \mathrm{m}$ ) adicionada à solução contendo 5,6 mM de glicose. Nossos resultados sugerem que o nervo vago (ramo pancreático) participa da regulação do processo secretório da insulina pelas células beta pancreáticas. Este efeito pode estar associado à modulação da respostas induzidas pela glicose e reguladas pelo neurotransmissor acetilcolina, considerado modulador da secreção de insulina.
\end{abstract}

Palavras chave: Acetilcolina. Insulina/Secreção. Carbacol. Células beta Pancreáticas. Sistema Nervoso Parassimpático.

\section{Introdução}

A insulina é o único hormônio protéico que expressa ações predominantemente hipoglicemiantes. Por esta razão, déficit na liberação de insulina produz severas desordens metabólicas, como o diabetes mellitus. A insulina é liberada da célula $\beta$ de ilhotas de Langerhans, um complexo de células endócrinas onde, 60 a $70 \%$ da população é constituída por células beta $(\beta)$, secretoras de insulina, 20 a $25 \%$, de célula alfa $(\alpha)$, secretoras de glucagon; $10 \%$ de células delta $(\delta)$, secretoras de somatostatina e cerca de $5 \%$ de células PP, responsáveis pela secreção de polipeptídio pancreático. ${ }^{1}$

Os secretagogos de insulina incluem nutrientes que são metabolizados pela célula $\beta$, (como: glicose, leucina, isoleucina, arginina), substâncias que estimulam o metabolismo de substratos endógenos e agen-
1. Docente do PPG Fisioterapia da Universidade Metodista de Piracicaba (UNIMEP), Piracicaba - S.P

2. Fisioterapeuta - Especialização em Fisioterapia Desportiva UNIMEP - Piracicaba,SP

3. Graduação em Fisioterapia - UNIMEP- Piracicaba, SP

4. Doutoranda em Fisioterapia - Universidade Federal de São Carlos, SP (UFsCAR)

5. Docente do Departamento de Fisiologia e Biofísica da Universidade de Campinas (UNICAMP) - Campinas, SP
Correspondência

Prof. Dr. Carlos Alberto da Silva casilva@unimep.br

Universidade Metodista de Piracicaba Faculdade de Ciências da Saúde - PPG-Fisioterapia Rodovia do Açúcar, Km 156 - Taquaral CEP: 13400-911 - Piracicaba - São Paulo - Brasil

Artigo recebido em 28/11/2008 Aprovado em 06/03/2009 
tes farmacológicos, os quais promovem alterações elétricas na membrana das células $\beta$ induzindo a secreção da insulina. ${ }^{2,3,4}$

O controle nervoso das funções pancreáticas é efetuado por ramificações parassimpáticas pré-ganglionares do vago que inervam as células das ilhotas. ${ }^{5}$ O núcleo motor dorsal do nervo vago supre a inervação pré-gangliônica para o pâncreas. ${ }^{6} \mathrm{~A}$ função secretomotora é exercida por um controle central efetuado pelos núcleos dorsal motor do vago e do trato solitário, áreas sob a influência de grupamentos neuronais do hipotálamo ventromedial e lateral. ${ }^{7}$ No abdome o tronco anterior do vago percorre a parede anterior do esôfago e se divide formando os ramos hepático, anterior gástrico e, em alguns casos, o celíaco acessório. $\mathrm{O}$ tronco posterior percorre a porção posterior do esôfago e se ramifica dando origem aos ramos celíaco e posterior gástrico. ${ }^{8}$

Diversos estudos do processo secretório da insulina, realizados com ratos normoglicêmicos, constataram que há uma secreção reflexa de insulina em resposta a estímulos gustativos, a qual é mediada pelo nervo vago. ${ }^{9,10}$ Têm sido relatadas três ações ligadas à estimulação muscarínica representado pelo aumento na permeabilidade ao $\mathrm{Na}^{+}$, aumento na permeabilidade ao $\mathrm{Ca}^{2+}$ e redução na permeabilidade ao $\mathrm{K}^{+11}$. O desaparecimento da primeira fase da secreção é um dos sinais precoces de início do estabelecimento do diabetes. O primeiro pico (pré-absortivo) da liberação de insulina, reflexamente induzido pelo alimento na cavidade oral, foi abolido pela vagotomia troncular. ${ }^{10,11}$ Por outro lado, o segundo pico de secreção de insulina, desencadeado pela presença do alimento na porção gastroduodenal, não parece ser devido à estimulação vagal direta das células $\beta$. Embora o primeiro pico sido tenha abolido pela vagotomia troncular completa, o segundo foi mantido em ratos diabéticos após transplante de tecido pancreático; portanto, mesmo ilhotas denervadas manifestam a resposta. ${ }^{12}$

Estudos com imunofluorescência verificaram que a estimulação muscarínica promove um substancial aumento no cálcio citosólico e pode ter relação com a geração de segundos mensageiros como o inositol tri-fosfato, adenosina monofosfato cíclico (AMPc) ou proteínas quinases. ${ }^{12,13}$

A proposta deste trabalho foi estudar os efeitos a médio prazo (15 e 30 dias) da vagotomia subdiafragmática seletiva sobre a permeabilidade ao $\mathrm{Ca}^{2+}$ na presença da glicose e o efeito potencializador da carbamilcolina sobre a estimulação com glicose.

\section{Material e Métodos}

Foram utilizados ratos Wistar, de 3 meses de idade, pesando entre 280 e $300 \mathrm{~g}$. Os animais foram mantidos em condições de fotoperíodo controlado (12:12 h, luz acesa às 6:00). Água e ração foram supridas ad libitum. Os ratos foram distribuídos nos grupos experimentais: controle e submetidos à vagotomia seletiva do ramo pancreático. Cabe ressaltar que o grupo controle (considerado íntegro) não foi submetido a nenhum procedimento cirúrgico. Os efeitos da vagotomia foram estudados a curto e médio prazo (15 e 30 dias após a cirurgia) sobre o fluxo de ${ }^{45} \mathrm{Ca}^{2+} \mathrm{em}$ ilhotas isoladas. A vagotomia foi efetuada sob anestesia com pentobarbital sódico (50mg/Kg de peso, ip) após tricotomia e assepsia com álcool na região abdominal. A seguir foi feita uma incisão no abdômen logo abaixo do externo, expondo a porção do esôfago abaixo do hiato esofagiano para evidenciar os troncos vagais, posterior e anterior, e as suas ramificações: gástricas, hepática, celíaca (pancreática) e celíaca acessória. ${ }^{13}$

$\mathrm{O}$ isolamento das ilhotas foi realizado segundo o método da colagenase. ${ }^{14}$ Para incubação e perfusão foi utilizado a solução de KREBS (mM; $\mathrm{Na}^{+}, 139,0$; $\left.\mathrm{K}^{+}, 5,0 ; \mathrm{Ca}^{2+}, 2,6 ; \mathrm{Mg}^{2+}, 1,0 ; \mathrm{Cl}^{-}, 123,6 ; \mathrm{HCO}_{3}^{-}, 24,0\right)$ acrescida de $0,5 \%(\mathrm{~m} / \mathrm{v})$ de albumina bovina sendo o pH equilibrado em 7,4 através de gaseamento com carbogênio. Depois de isoladas, 250 ilhotas foram depositadas em câmara forrada com filtro de acetato de celulose ( $8 \mu \mathrm{m}$, Millipore, France). O sistema de perfusão foi constituído por um banho-maria para manter constantes a temperatura $\left(36 \pm 2^{\circ} \mathrm{C}\right)$ e a pressão das soluções de perfusão impelida por uma bomba peristáltica de 2 canais (Minipuls 2, Gilson Medical Electronics, França) para impulsionar as soluções perfusoras para a câmara contendo ilhotas. As soluções de KREBS, controle e experimental, que perfundiram, alternadamente, as ilhotas eram provenientes de 2 frascos mantidos no banho-maria e foram continuamente gaseadas. O efluente foi coletado a cada dois minutos, em frascos apropriados para a contagem de radioatividade. O fluxo foi ajustado para $1 \mathrm{ml} /$ minuto. A defasagem entre a mudança de posição das válvulas (torneiras) e o início da troca das soluções nas câmaras foi devidamente computado na elaboração dos gráficos.

\section{Protocolos Experimentais}

Inicialmente foi avaliada a resposta das ilhotas à glicose. Na primeira fase do efluxo (controle) as 
ilhotas foram perfundidas com solução de KREBS desprovida de glicose e, após o $10^{\circ}$ minuto, foi trocada pela solução de KREBS contendo $16,7 \mathrm{mM}$ de glicose. Seqüencialmente foi avaliada a resposta à carbamilcolina de forma que inicialmente as ilhotas foram perfundidas com solução de KREBS contendo 5,6 mM de glicose $(\mathrm{G} 5,6)$ a qual após o $10^{\circ}$ minuto foi trocada pela solução de KREBS contendo glicose 5,6 mM e $100 \mathrm{mM}$ de carbamilcolina (G 5,6 + CCh). Para analisar os efeitos da vagotomia seletiva sobre a permeabilidade da membrana da célula b sobre o efluxo de ${ }^{45} \mathrm{Ca}^{2+}$, além da descrição das variações do fluxo induzido pelas mudanças indicadas no protocolo experimental, foram calculadas as áreas sob as curvas (expressas em unidade arbitrária) para os intervalos entre o $42^{\circ}-50^{\circ}$ minutos. As estimativas dos valores das áreas sob as curvas foram obtidas através do programa ORIGIN 2.8. $\mathrm{Na}$ análise estatística as áreas sob a curva dos efluxos de ${ }^{45} \mathrm{Ca}^{2+}$ foram comparados através da análise de variância, seguida pelo teste de Tukey. Foram admitidas como significativas às diferenças $\mathrm{p}<0,05$.

\section{Resultados}

Mudanças em fluxos iônicos são eventos iniciais na cadeia de reações que levam à secreção de insulina induzida por glicose. Estes envolvem inicialmente variações do efluxo de $\mathrm{K}^{+}$e de $\mathrm{Ca}^{2+}$. Primeiramente, estudamos as modificações dos fluxos de ${ }^{45} \mathrm{Ca}^{2+}$, induzidas pela estimulação de ilhotas de Langerhans de ratos com 16,7mM de glicose. Em ilhotas isoladas de ratos controle (íntegros), 6 minutos após a introdução de 16,7 mM de glicose o efluxo dobrou em relação aos últimos minutos do período controle, sendo mantido em platô até o final da perfusão como pode ser observado na Figura 1.

A comparação entre as áreas do período controle e experimental mostra uma área menor nos grupos vagotomizados 15 e 30 dias $(15 \mathrm{D}=12,66 \pm 1,71$; $30 \mathrm{D}=12,06 \pm 2,16$ unidades arbitrárias) em comparação a calculada para o grupo controle $(C=21,8 \pm 5,67$ unidade arbitrária). Desta forma, ilhotas isoladas de ratos 15 ou 30 dias após serem vagotomizados não demonstraram variação da razão de efluxo, após a introdução de 16,7 mM de glicose (Figura 1).

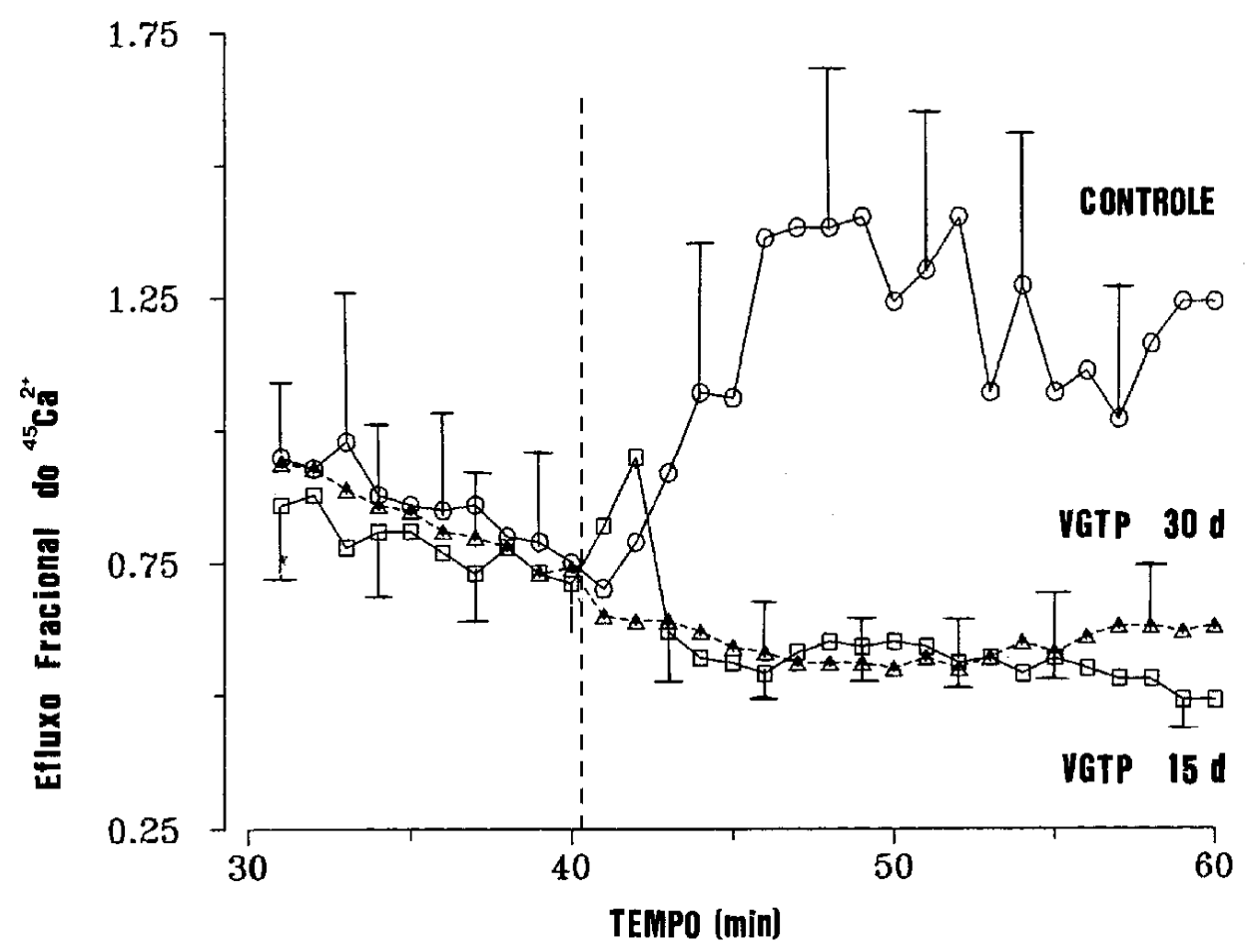

Figura 1: Efeito da adição de glicose sobre a dinâmica do efluxo fracional de ${ }^{45} \mathrm{Ca}^{2+}$ em ilhotas pancreáticas isoladas de ratos controle e vagotomizados após o período pós-operatório de 15 ou 30 dias denominados respectivamente de VGTP15 e VGTP30. Após adaptação, as ilhotas foram perfundidas com solução de KREBS-bicarbonato desprovida de glicose até o $40^{\circ}$ minutos. A linha vertical interrompida indica o início da perfusão com 16,7 mM de glicose. Cada ponto representa a média de 4 câmaras, cada qual, contendo 250 ilhotas. 
Também avaliamos se a vagotomia promoveu alterações da sensibilidade das células $\beta$ à carbamilcolina (como substituto de acetilcolina) em presença de 5,6 mM de glicose, sobre o efluxo de ${ }^{45} \mathrm{Ca}^{2+}$ como mostra a figura 2. Em ilhotas isoladas de ratos controle, a adição de carbamilcolina $(100 \mu \mathrm{M})$ à solução perfusora induziu aumento transiente do efluxo de ${ }^{45} \mathrm{Ca}^{2+}$ após os primeiros 5 minutos, permanecendo elevada em relação ao período precedente por $8 \mathrm{mi}-$ nutos $(\mathrm{p}<0,05)$, este aumento foi também calculado pela comparação entre as áreas do período controle e experimental o qual mostrou que a área do controle foi maior do que as áreas dos grupos vagotomizados 15 e 30 dias (17,76 $\pm 3,92$ controle; $10,31 \pm 2,04$ vagotomizado 15 dias; $11,19 \pm 2,01$ vagotomizado 30 dias). No entanto, nas ilhotas isoladas de ratos submetidos à vagotomia posterior (ramo pancreático), a resposta à carbamilcolina foi abolida, mantendo a mesma velocidade de efluxo do período que antecedeu a adição da carbamilcolina. Estes resultados sugerem que tenha ocorrido redução da sensibilidade colinérgica nas ilhotas nos 15 e 30 dias após a vagotomia.

\section{Discussão}

Dentre os inúmeros fatores que regulam a secreção de insulina, destacam-se os hormônios, os íons, vários fármacos, os co-fatores metabólicos e principalmente os nutrientes, como a glicose e alguns aminoácidos. O controle neural da secreção da insulina assume papel muito importante na regulação da secreção, modulando a atividade das células $\beta$ antes, durante e após a ativação do mecanismo secretor. A antecipação de resposta das ilhotas, aumentando a secreção de insulina antes do aumento de glicose no fluxo sangüíneo pancreático é chamada de fase cefálica da secreção de insulina. ${ }^{15}$

Em indivíduos sadios, o controle deste status reflete a atividade conjunta do sistema nervoso simpático e parassimpático. A inervação parassimpática desempenha papel estimulatório, usualmente chamado potencializador, através dos receptores muscarínicos M3 que participam da modulação do processo secretório da insulina induzida pela glicose. ${ }^{16,17}$

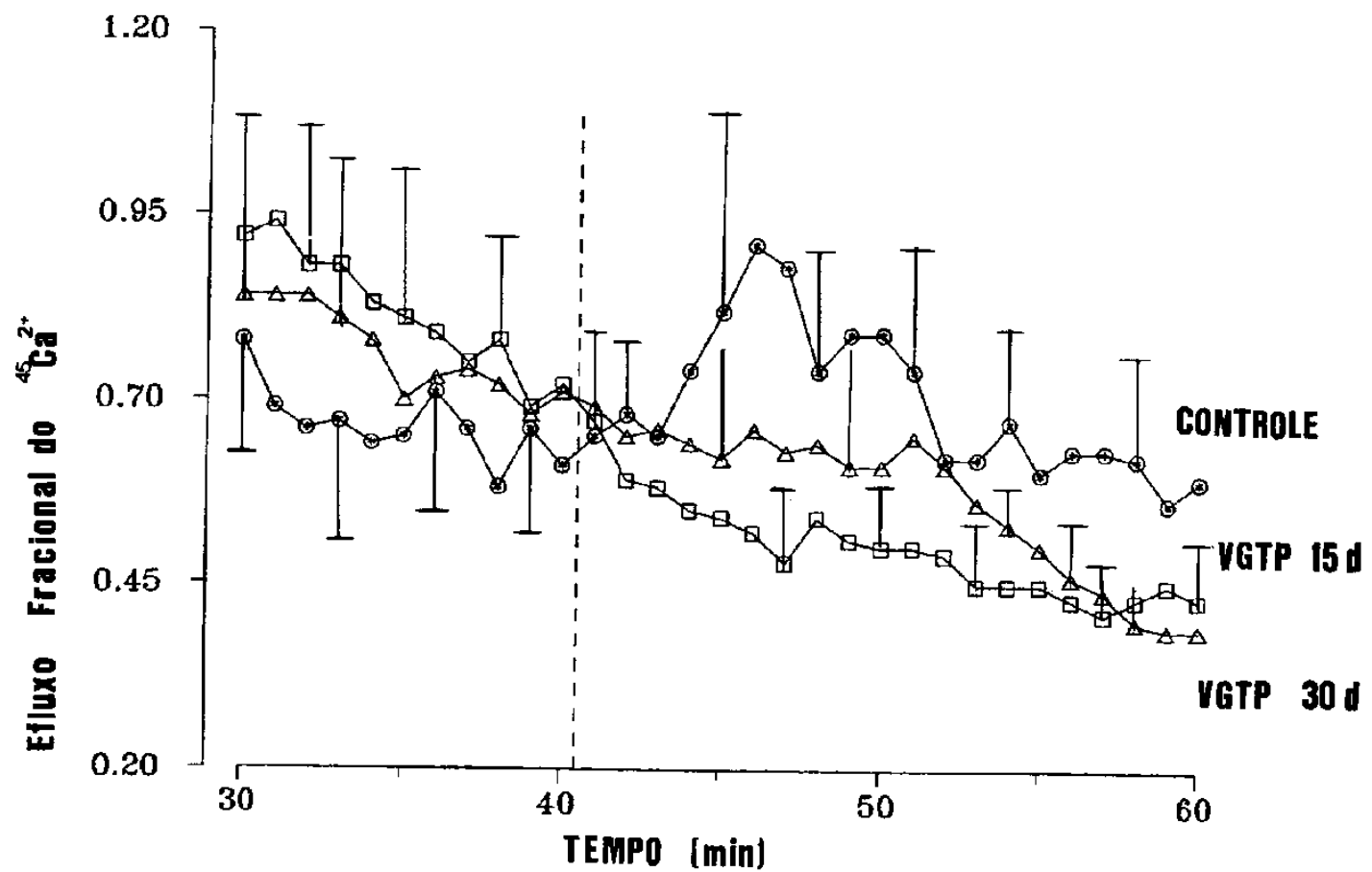

Figura 2: Efeito de $(100 \mu \mathrm{M})$ de carbamilcolina sobre a constante de efluxo fracional de ${ }^{45} \mathrm{Ca}^{2+}$ em ilhotas pancreáticas isoladas de ratos controle e de ratos submetidos à vagotomia pancreática 15 e 30 dias denominados respectivamente de VGTP15 e VGTP30. As ilhotas foram perfundidas em solução de KREBS-bicarbonato contendo $5,6 \mathrm{mM}$ de glicose, durante toda a perfusão. A linha interrompida indica o momento de introdução da carbamilcolina. Cada ponto representa a média de 04 câmaras, cada qual contendo 250 ilhotas. 
O desaparecimento da fase cefálica da secreção é uma das ocorrências mais precoces no estabelecimento do diabetes e há inúmeras evidências indicando que alterações da função vagal estão envolvidas. ${ }^{18,19}$

A participação da neuroregulação no processo secretório de insulina tem sido objeto de estudo em humanos submetidos à vagotomia troncular e é muito importante de ser considerada o seu comprometimento em indivíduos submetidos a cirurgias em áreas ou próximas ao pâncreas, fígado e estômago. ${ }^{20}$ Diversos autores têm avaliado a participação do ramo celíaco vagal, suas relações com o sistema hepato-portal bem como o envolvimento das vias vagais eferentes na regulação da secreção de insulina. ${ }^{21}$ A modulação da secreção de insulina pelo sistema nervoso parassimpático foi demonstrada por meio de estimulação elétrica direta do tronco vagal ou dos ramos do vago posterior comparando as respostas com a estimulação de outros ramos vagais. ${ }^{8}$

A secreção de insulina está intimamente relacionada às variações da condutância iônica e da concentração de $\mathrm{Ca}^{2+}$ das células $\beta$. A compreensão do mecanismo de secreção de insulina avançou muito ao longo dos últimos 20 anos, em especial quanto aos eventos que se seguem ao estímulo por glicose ${ }^{22}$.

Diferentes estudos têm relatado que tanto a glicose como a carbamilcolina, promovem aumento do efluxo de ${ }^{45} \mathrm{Ca}^{2+}$ que é resultante da combinação entre o cátion acumulado no interior das células e aquele resultante do influxo e provocado pelo estímulo. ${ }^{22,23}$ Em nosso estudo, a secção do ramo pancreático vagal provocou alterações da permeabilidade da membrana ao ${ }^{45} \mathrm{Ca}^{2+}$, tornando-a não responsiva à glicose. $\mathrm{Na}$ ausência da inervação parassimpática pode deve ter ocorrido alterações em alguma das etapas iniciais do acoplamento estímulo-secreção, dependente da glicose, as quais precedem as mudanças na permeabilidade ao $\mathrm{Ca}^{2+}$, uma vez que, o sistema nervoso parassimpático exerce ação moduladora na funcionalidade da célula $\beta$.

Também a resposta das ilhotas ao estímulo com carbamilcolina foi abolida pela vagotomia pancreática. Na década de 90, existiu uma grande divergência quanto à ação da carbamilcolina sendo sugerido que a substância poderia provocar alterações na permeabilidade da membrana, modificando o fluxo iônico e com isto mudando o padrão fisiológico das células $\beta$ de ratos e de camundongos íntegros em presença de glicose em concentração próxima ao limiar de estimulação.

Outra alternativa para o aumento do efluxo de ${ }^{45} \mathrm{Ca}^{2+}$, estimulados pela acetilcolina, poderia envolver a participação dos canais de $\mathrm{Na}^{+}$. Neste sentido, foi verificado que retirando-se $\mathrm{o} \mathrm{Na}^{+}$da solução extracelular, foram abolidos os efeitos da acetilcolina sobre a atividade elétrica e sobre estes fluxos iônicos, sugerindo uma relação funcional entre a ação colinérgica e a permeabilidade ao $\mathrm{Na}^{+}$, favorecendo a despolarização da célula beta. ${ }^{24}$

Os presentes resultados mostram que a vagotomia pancreática, afeta a permeabilidade da membrana ao $\mathrm{Ca}^{2+}$, sugerindo que a sensibilidade à carbamilcolina (aqui utilizada em substituição à acetilcolina para obter maior duração do efeito) desapareceu em virtude da previsível diminuição de seus receptores na membrana. Todavia, como a sensibilidade à glicose também foi abolida é possível que ambas as formas de estímulo partilhem, ou ativem alguma etapa inicial do mecanismo de secreção de insulina que antecede às modificações das permeabilidades iônicas da membrana.

Os resultados mostram que a resposta ao estímulo induzido por glicose ou por carbamilcolina em célula $\beta$ de ratos vagotomizados foi alterada, reduzindo o aumento do efluxo que ocorre em ilhotas de ratos controle quando estimuladas por agentes secretagogos ou potencializadores da secreção. É possível que a permeabilidade da membrana esteja afetada devido à ausência do trofismo mediado pela inervação vagal.

\section{Agradecimento especial}

Dedico este trabalho ao Prof. Dr. Antonio Ari Gonçalves, professor do Departamento de Fisiologia e Biofísica da UNICAMP, um cientista que na sua vida acadêmica dedicou-se ao ensino e pesquisa na área de Fisiologia e Biofísica sendo um exemplo de formador de docentes pesquisadores. Meu muito obrigado e orgulho de ter sido seu aluno. 


\begin{abstract}
The participation of the parasympathetic nervous system in insulin secretion modulation is clearly evident during the cephalic phase that follows the sensorial stimulus provoked by food in the mouth. The objective of this study was to evaluate if selective subdiaphragmatic vagotomy of the pancreatic branch could alter ${ }^{45} \mathrm{Ca}^{2+}$ permeability in the plasmatic membrane of pancreatic $\beta$ cell. To assess the effects of vagotomy, we used glucose and the potentializer carbamylcholine on the glucose effects. Analysis of ${ }^{45} \mathrm{Ca}^{2+}$ efflux was accomplished in isolated islets by digestion with collagenase and perfused with KREBS and carbamylcholine in rats from groups control and denervaded. After 15 and 30 days of the pancreatic branch vagotomy, the isolated islets did not respond to a glucose stimulus of $16,7 \mathrm{mM}$ and also presented alteration in carbamylcholine sensibility (CCh $100 \mu \mathrm{m})$ when added to the solution containing 5,6 $\mathrm{mM}$ of glucose. Our results suggest that the vagus nerve (pancreatic branch) contributes with regulation of insulin secretory process of pancreatic $\beta$ cells. This effect could be associated to the modulation of responses induced by glucose and the regulation of acetylcholine, a neurotransmitter modulator of insulin secretion.
\end{abstract}

Key words: Acetylcholine. Insulin/Secretion. Carbamylcholine. Insulin-Secreting Cells. Parasympathetic Nervous System.

\section{Referências Bibliográficas}

1. Cingolani HE, Houssay AB. Fisiologia Humana de HOUSSAY. $7^{\mathrm{a}}$ ed. Porto Alegre: ArtMed; 2004.

2. Dunning BE, Havel PJ, Taborsky JGT. Autonomic control of insulin secretion. In: Frontiers of insulin secretion and pancreatic beta cell research. Eds Flatt P \& Lenzen S. pp 343351, Smith Gordon, UK. 1994.

3. Flatt PR. Hormonal and neural control of endocrine pancreatic function. In textbook of diabetes, $2^{\text {nd }}$ ed. pp91-97, UK Pickup and G Willians, editors, Oxford Blackwell.

4.Stokes $\mathrm{Cl}$, Rinzel J. Diffusion of extracellular $\mathrm{K}^{+}$can synchronize bursting oscillation in a model islets of Langerhans. Biophys J. 1993; 65:597-607.

5. Bonner Weier S. Anatomy of islets of Langerhans. In. The endocrine pancreas. Ed. Salmons e., pp 15-27, Raven Press, New York. 1991.

6. Siaud P, Puech R, Assenmacher I, Alonso G. Adrenergic innervations of the dorsal vagal motor nucleus: possible involvement in inhibitory control of gastric acid and pancreatic insulin secretion. Cell Tissue Res. 1990, 259: 535-42.

7. Doretto D. Fisiopatologia Clinica do Sistema Nervoso. Rio de Janeiro: Atheneu; 1989, 127p.

8. Berthoud HR, Fox EA, Powley TL, Localization of vagal pregaglionics that stimulate insulin and glucagon secretion. Am J Physiol. 1990; 258:160-8.

9. Louis-Sylvestre J, Preabsorptive insulin release and hypoglycemia in rats. Am J Physiol. 1976; 230:56-60.

10. Steffens $A B$. Influence of the oral cavity on insulin release in the rat. Am J Physiol. 1976; 230: 1411-5.

11. Pakhtusova N, Zaonstrovskaya L, Lindstrom $P$, Larsson-Nyren G. Cell-specific $\mathrm{Ca}^{2+}$ responses in glucose stimulated single and aggregated -cells. Cell Calcium. 2003; 34:121-9.

12. Rajan As, Hill RS, Boyd AE. Effect of rise in cAMP levels in $\mathrm{Ca}^{2+}$ influx through voltage-dependent $\mathrm{Ca}^{2+}$ channels in Hit cells: second-messenger synarchy in ${ }^{\sim}$-cells. Diabetes. 1989; 38:874-80.
13. Lautt WW. Hepatic parassympathetic neurophathy as cause of maturity onset diabetes? Gen Pharmacol. 1979; 11:343-5.

14. Bordin S, Boschero AC, Carneiro EM, Atwater I. Ionic mechanism involved in the regulation of insulin secretion by muscarinic agonist. J Membr Biol. 1995; 148: 177-84.

15. Gautam D, Jeon J, Li JH, Han SJ, Handan FF, Cui Y, Lu H, Deng C, Gavrilova O, Wess J. Metabolic roles of the M3 muscarinic acetylcholine receptor studied with M3 receptor mutant mice: a review. J Recept Signal Transduct Res. 2008; 28: 93-108.

16. Gautam D, Li JH, Han SJ, Duttaroy A, Mears A, Handan FF, Cui $\mathrm{Y}$, Lu H, Wess J, Jeon J. Role of M3 muscarinic acetylcholine receptor in beta-cell function and glucose homeostasis. Diabetes Obes Metab. 2007; 9: 158-69.

17. Renuka TR, Robinson R, Paulose CS. Increased insulin secretion by muscarinic $\mathrm{M} 1$ and $\mathrm{M} 3$ receptor function from rat pancreatic islet in vitro. Neurochem Res. 2006; 31: 313-20.

18. Louis-Sylvestre J,Giachetti I, Lemagnen J. A non invaseve test for the completeness of vagotomy to the pancreas. Physiol Behav. 1981; 26: 485-8.

19. Cardoso DE, França LP, Chinen E, Moraes AA, Ferreira AT, França JP. Morphologic evaluation and $\mathrm{Ca}^{2+}$ mobilization by glicose and acetylcholine in human pancreatic cells. Arq Bras Endocrinol Metab. 2007; 51: 431-6.

20. Niijima, A. Neural control of blood glucose level. Jpn J Physiol. 1986; 36: 826-41.

21. Gilon P, Henquin JC. Mechanism and physiological significance of the cholinergic control of pancreatic beta-cell function. Endocr Rev. 2001; 22: 565-604.

22. Leibiger BI, Leibiger B, Berggren PO. Insulin feedback action on pancreatic $\beta$-cell function. FEBS Letters. 2002; 532:1-6.

23. Nakano K, Suga S, Takeo T, Ogawa Y, Suda T. Intracellular $\mathrm{Ca}^{2+}$ modulation of ATP-sensitive $\mathrm{K}^{+}$channel activity in acetylcholine-induced activation of rat pancreatic B-cells. Endocrinology. 2002; 143: 569-76.

24. Henquin JC, Henquin M. The muscarinic receptor subtype in mouse pancreatic B-cell. FEBS Letters. 1988; 236: 89-92. 